\title{
Stability-Indicating RP-HPLC Assay for Simultaneous Determination of Chlorpheniramine Maleate and Prednisolone in Veterinary Injection
}

\author{
Amir Ali ${ }^{1}$, Umar Farooq ${ }^{1 *}$, Mahmood Ahmed ${ }^{2}$, Muhammad Makshoof Athar ${ }^{1}$, M. Salman ${ }^{1}$, Saira Arif ${ }^{1}$, \\ Kashif Nadeem ${ }^{3}$ and Hassan $\mathrm{Naz}^{3}$ \\ Institute of Chemistry, University of the Punjab, Lahore, 54590, Pakistan \\ Renacon Pharma Limited, Lahore, 54600, Pakistan \\ Schazoo Pharmaceutical Laboratories, Lahore-Jaranwala Road, Sheikhupura, Pakistan
}

Received: 11 Jan 2019; accepted: 10 May 2019

\begin{abstract}
The present work described a simple, rapid, sensitive, accurate, and precise method for simultaneous determination of chlorpheniramine maleate (CHRM) and prednisolone acetate (PRED) in injection samples by high-performance liquid chromatography (HPLC) coupled with UV-Vis detection. Chromatographic separation was accomplished, employing isocratic mode and a mobile phase comprised of acetonitrile and a phosphate buffer $\left(50: 50, v / v, 30^{\circ} \mathrm{C}\right)$, adjusted to $\mathrm{pH} 3.0$. The flow rate used was $1.0 \mathrm{~mL} / \mathrm{min}$ on a Thermo Hypersil ODS C18 column $(5 \mu \mathrm{m}, 4.6 \times$ $250 \mathrm{~mm}$ ), and the injection volume of sample was $20 \mu \mathrm{L}$. Analysis of CHRM and PRED was performed at a wavelength of $254 \mathrm{~nm}$. The runtime for analysis was $12.5 \mathrm{~min}$, and the retention times of CHRM and PRED were found to be 2.81 and $5.07 \mathrm{~min}$, respectively. The calibration graph showed linearity over the concentration range 10$70 \mu \mathrm{g} / \mathrm{mL}$ for CHRM and $20-140 \mu \mathrm{g} / \mathrm{mL}$ for PRED with a coefficient of determination $\left(R^{2}\right) \geq 0.9986$. Repeatability and reproducibility (expressed as \% RSD) were lower than 1.72 and $1.47 \%$, respectively. The proposed HPLC method was demonstrated to be simple and rapid for the determination of CHRM and PRED in injection formulation, providing recoveries between 101.6-102.3\%, whereas complete separation of degradation products, from analyte under investigation, provided the specificity of the proposed HPLC method.
\end{abstract}

Keywords: antihistamines, corticosteroid, HPLC, validation, stability-indicating method

\section{Introduction}

Chlorpheniramine maleate (CHRM, Figure 1a) is chemically 3-(4-chlorophenyl)- $N, N$-dimethyl-3-pyridin-2-ylpropan1 -amine and an antihistamine drug commonly used to treat common cold, hay-fever, and allergic conditions, such as urticaria and rhinitis. CHRM is one of the most widely used antihistamines for small animal veterinary practices. CHRM is combined with narcotic or aminophylline for treatment of cough and upper respiratory symptoms [1-3]. Prednisolone (PRED, Figure 1b), chemically $11 \beta, 17 \alpha, 21$-trihydroxypregna-1,4-diene-3,20-dione 21-acetate, is a corticosteroid widely used in inflammatory conditions and as an immunosuppressive drug [4-5]. From a literature survey, it is revealed that different analytical methods were available for the estimation of prednisolone acetate and chlorpheniramine maleate individually or in fixed-dose combinations with other drugs. The analytical methods existed for PRED and CHRM, in combination with other drugs, including micellar electrokinetic chromatography [6-7], mass spectrophotometry [8-9], highperformance liquid chromatography (HPLC) [10-12], FT-Raman spectroscopy [13], and thin-layer chromatography densitometry [14]. To the best of our knowledge, the simultaneous determination of chlorpheniramine maleate and prednisolone acetate in pharmaceutical formulations by HPLC with a diode array detector (HPLC-DAD) has not been reported yet. HPLC-DAD is mostly used due to many advantages, such as

*Author for correspondence: Institute of Chemistry, University of the Punjab, Lahore, E-mail: umar.chem@pu.edu.pk, Fax: 0092-42-99230998. high sensitivity, rapid analysis, and high selectivity. According to the requirements of the International Conference on Harmonization ( $\mathrm{ICH})$, stress testing during method development is a part of developmental strategy. Stress studies are usually carried out under severe conditions rather than accelerated conditions and provide information about drug's inherent stability. Stability study approach is being extended to fixed-dose pharmaceutical combinations to enable precise and accurate estimation of drugs in the presence of degradation products [1516]. To develop the stability-indicating methods, force degradation is used to demonstrate specificity. That's why it should be performed before implementation of stability studies to make certain that the developed analytical method is the stability-indicating one. Therefore, there is a challenge to develop stability-indicating reversed-phase (RP)-HPLC method for the separation and determination of CHRM and PRED from each other and degradation products. Hence, an attempt has been made to develop a precise, linear, accurate, repeatable, reproducible, robust, and specific HPLC method for the determination of CHRM and PRED in the presence of their degradation products.

The objective of the present research work was to develop a simple, specific, precise and accurate new stability-indicating liquid chromatographic (HPLC) method for the simultaneous determination of CHRM and PRED in injection samples for veterinary uses. The developed HPLC method was validated according to the ICH guidelines [17] and successfully applied to determine CHRM and PRED in fixed-dose pharmaceutical combinations. The results showed that the developed method could be useful for quality control and stability studies.

This is an open-access article distributed under the terms of the Creative Commons Attribution-NonCommercial 4.0 International License (https://creativecommons.org/licenses/by-nc/4.0/), which permits unrestricted use, distribution, and reproduction in any medium for non-commercial purposes, provided the original author and source are credited, a link to the CC License is provided, and changes - if any - are indicated. 


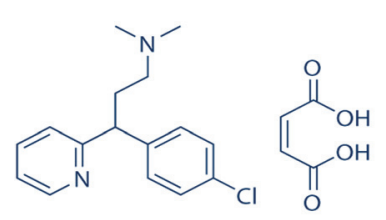

a

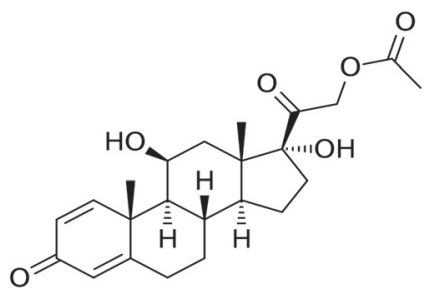

$b$
Figure 1. Chemical structures of CHRM (a) and PRED (b)

\section{Experimental}

2.1. Chemicals and Reagents. CHRM and PRED reference standards were obtained from Schazoo Pharmaceutical Laboratories (Lahore, Pakistan). Diammonium hydrogen phosphate $\left(\left(\mathrm{NH}_{4}\right)_{2} \mathrm{HPO}_{4}\right)$, phosphoric acid $\left(\mathrm{H}_{3} \mathrm{PO}_{4}\right.$ $85 \%$ ) and sodium hydroxide were obtained from Sigma Aldrich (St. Louis, USA). Acetonitrile (ACN) and methanol $(\mathrm{MeOH})$ were of HPLC-grade and supplied by Merck (Darmstadt, Germany). Double distilled water used throughout the experiment was obtained using a Milli-Q system from Millipore (Bedford, MA, USA). Other chemicals and solvents used were of analytical reagent grade. Injections containing CHRM $(4.0 \mathrm{mg} / \mathrm{mL})$ and PRED $(10.0 \mathrm{mg} / \mathrm{mL})$ were collected from a local market.

2.2. Chromatographic Conditions. For HPLC analysis, a PG LC200, high-performance liquid chromatographic system with a LC210 Pump, a PC220 UV/Vis detector, a LC250 column oven, a LC240 vacuum degasser, and LC Win 1.0 Software was used. The best separation of CHRM, PRED, and degradation products was achieved on a Thermo Hypersil ODS C18 column $(5 \mu \mathrm{m}, 4.6 \times 250 \mathrm{~mm})$. The mobile phase was comprised of $\mathrm{ACN}$ and a phosphate buffer pumped in a ratio of 50:50 $(\mathrm{v} / \mathrm{v})$ at $\mathrm{pH} 3.0$ adjusted by dilute $\mathrm{NaOH}$ ( $\mathrm{pH}$ meter, Orion 5 Star, Thermo Scientific, UK). The detection was carried out at a column temperature $30{ }^{\circ} \mathrm{C}$ by injecting $20 \mu \mathrm{L}$ of the sample, while the flow rate and wavelength were set at $1.0 \mathrm{~mL} / \mathrm{min}$ and $254 \mathrm{~nm}$, respectively. All the solutions including standards, samples, and mobile phase were filtered by a $0.45-\mu \mathrm{m}$ nylon filter (Sartorius, Germany) before injection into the LC system. Peak integration and quantification were performed by using LC Win 1.0 software.

2.3. Standard and Sample Solutions Preparation. Accurately weighed CHRM (20 mg) and PRED (50 mg) were dissolved in methanol and diluted to a final volume of $100 \mathrm{~mL}$. A portion $(10.0 \mathrm{~mL})$ of the above prepared stock solutions was diluted to $100 \mathrm{~mL}$ with methanol to prepare working standard solutions with a final concentration of $20.0 \mu \mathrm{g} / \mathrm{mL}$ (CHRM) and $50.0 \mu \mathrm{g} / \mathrm{mL}$ (PRED). A small volume $(5.0 \mathrm{~mL})$ of the sample solution, from injection vial containing CHRM and PRED, was taken in a $100-\mathrm{mL}$ flask, dissolved in methanol and made the volume up to the mark with methanol. The working sample solution was prepared by diluting $10 \mathrm{~mL}$ of the above prepared sample solution to $100.0 \mathrm{~mL}$ with methanol to achieve a final concentration of $20.0 \mu \mathrm{g} / \mathrm{mL}(\mathrm{CHRM})$ and $50.0 \mu \mathrm{g} / \mathrm{mL}$ (PRED).

2.4. System Suitability Testing. The working standard solution of CHRM $(20 \mu \mathrm{g} / \mathrm{mL})$ and PRED $(50 \mu \mathrm{g} / \mathrm{mL})$ was injected 6 times on HPLC, on 3 separate days, and conformity of chromatographic parameters was done as explained in United States Pharmacopeia (USP) including retention time $(<2 \%$ relative standard deviation [RSD]), peak area $(<2 \%$ RSD), tailing factor $(<2)$, selectivity factor $(>1)$, resolution $(>2)$, and theoretical plate count $(>1000)$ [18-19].
2.5. Validation Studies. Validation studies were performed according to the ICH guidelines [20] in terms of specificity, linearity, accuracy, precision, limit of detection (LOD), and limit of quantitation (LOQ).

2.5.1. Linearity. For LC-based methods (HPLC), the linear dynamic range was selected within $10-70 \mu \mathrm{g} / \mathrm{mL}$ for CHRM and $20-140 \mu \mathrm{g} / \mathrm{mL}$ for PRED. A linear calibration curve in the form of $y=a x+b$ was obtained by plotting the peak area (y) of the drugs CHRM and PRED in triplicate against the nominal concentration $(x)$ of 7 concentrations of CHRM and PRED, whereas $a$ is the slope of the calibration curve and $b$ is the intercept. Linear regression equation was demonstrated, and the necessary parameters were tabulated. The resultant parameters of the linear regression, including the standard deviation (SD) of the response based on the slope and intercept, were used to determine the LOD and LOQ. The LOD and LOQ were defined as $3.3 \sigma / S$ and $10 \sigma / S$, respectively [11, 2125], where $\sigma$ is standard deviation, and $S$ is slope of the regression line.

2.5.2. Accuracy. The accuracy of the method was determined, by spiking in triplicate a known amount of pure drug to the pre-analyzed injections at 50,100 , and $150 \%$ of analyte in the dosage formulation. The resulting final concentrations of $30.0,40.0$, and $50.0 \mu \mathrm{g} / \mathrm{mL}$ for CHRM and $75,100.0$, and $125.0 \mu \mathrm{g} / \mathrm{mL}$ for PRED were obtained.

2.5.3. Precision. Precision were determined at different concentrations $(30.0,40.0$, and $50.0 \mu \mathrm{g} / \mathrm{mL}$ for CHRM and 75 , 100.0 , and $125.0 \mu \mathrm{g} / \mathrm{mL}$ for PRED), represented by mean recovery and \%RSD. The intra-day precision (repeatability) was evaluated by 5 replicates on one day, whereas the inter-day precision (reproducibility) was determined over 3 consecutive days.

2.6. Forced Degradation Studies. Forced degradation studies for stability indicating assay, by the proposed HPLC method, were performed under acidic, basic, oxidative, photolytic, and thermal conditions at a final concentration of $20 \mu \mathrm{g} / \mathrm{mL}$ for CHRM and $50 \mu \mathrm{g} / \mathrm{mL}$ for PRED from their commercial product under investigation. The stock solution was separately treated with $\mathrm{HCl}(0.1 \mathrm{M})$ and $\mathrm{NaOH}(0.1 \mathrm{M})$ for acidic and basic hydrolysis, whereas $\mathrm{H}_{2} \mathrm{O}_{2}(3.0 \% \mathrm{v} / \mathrm{v})$ was employed for oxidative stress ( $\left.1 \mathrm{~h}, 75 \% \mathrm{RH} / 40{ }^{\circ} \mathrm{C}\right)$. Photolytic stress was performed after exposing the solid form for $6 \mathrm{~h}$ under UV $(254 \mathrm{~nm})$. For thermal stress, the solid form was kept in an oven for $6 \mathrm{~h}$ at $100{ }^{\circ} \mathrm{C}$. After the described time, the stressed compound was dissolved in methanol, and $10.0 \mathrm{~mL}$ of these stock solutions were then diluted to $100 \mathrm{~mL}$ using the mobile phase.

\section{Results and Discussion}

The main goal of the developed HPLC method is to separate closely eluting degradation products from active pharmaceutical ingredients (APIs). During method development, different chromatographic conditions, such as stationary phase and mobile phase compositions, were employed and optimized by running degradation samples.

3.1. Optimization of Chromatographic Conditions. An HPLC method was developed for simultaneous determination of CHRM and PRED in liquid dosage form. To achieve sufficient resolution of the target compound, the presence of interfering substances, including excipients and matrix effect, is vital in developing the liquid chromatographic (LC) method. The present method was based on optimizing onefactor-at-a-time strategy. In the first step, a UV absorption spectrum was taken in the range of $200-400 \mathrm{~nm}$, resulting in a maximum absorbance at $254 \mathrm{~nm}$ for both analytes. Different columns with various stationary phases like Thermo Hypersil 
Table 1. Results of tested stationary phase

\begin{tabular}{lccccc}
\hline Column & Analyte & $R_{s}$ & $T$ & $k^{\prime}$ & $N$ \\
\hline Thermo Hypersil ODS, C18 & CHRM & -7.84 & 1.02 & 2.96 & 4665 \\
$(250 \times 4.6 \mathrm{~mm}, 5 \mu \mathrm{m})$ & PRED & & 1.12 & 6.14 & 5123 \\
Venusil XBP C18 & CHRM & -6.81 & 1.32 & 2.80 & 3451 \\
$(250 \times 4.6 \mathrm{~mm}, 5 \mu \mathrm{m})$ & PRED & & 1.39 & 6.01 & 3654 \\
Purospher $^{\circledR} \mathrm{RP}-18, \mathrm{C} 18$ & CHRM & -6.13 & 1.85 & 2.73 & 3857 \\
$(250 \times 4.6 \mathrm{~mm}, 5 \mu \mathrm{m})$ & PRED & & 1.73 & 5.69 & 3078
\end{tabular}

$R_{\mathrm{S}}$ : Resolution; $T$ : Tailing Factor; $k^{\prime}$ : Capacity factor; $N$ : Theoretical plates. Acceptance criteria $\left(R_{\mathrm{s}}>2.00 ; T<2.00 ; k^{\prime}>1.00 ; N>1000\right)$. Working conditions: mobile phase 50:50 (ACN-phosphate buffer; $\mathrm{pH}$ $=3.0)$ at $254 \mathrm{~nm}$, flow rate: $1.0 \mathrm{~mL} / \mathrm{min}$; column temperature: $30^{\circ} \mathrm{C}$.

ODS, C18 $(250 \times 4.6 \mathrm{~mm}, 5 \mu \mathrm{m})$, Venusil XBP C18 $(250 \times$ $4.6 \mathrm{~mm}, 5 \mu \mathrm{m})$, and Purospher ${ }^{\circledR} \mathrm{RP}-18, \mathrm{C} 18(250 \times 4.6 \mathrm{~mm}$, $5 \mu \mathrm{m})$ were employed for the separation of CHRM, PRED, and their degradation products (Table 1). The optimum separation was achieved using Thermo Hypersil ODS, C18 $(250 \times 4.6 \mathrm{~mm}, 5 \mu \mathrm{m})$, having the advantages of separating 2 drugs from their degradation products with good retention time.

The 2 organic solvents (acetonitrile and methanol) have been tried for the optimization of the HPLC method. Acetonitrile was selected initially due to greater reported elution strength [26]. The different ratios of water and acetonitrile were used, but the presence of phosphate buffer improved the separation of components. The effect of $\mathrm{pH}$ on the separation of components was studied from $\mathrm{pH}$ range 2.0 to 7.0. It was observed that by the increase in $\mathrm{pH}$, the retention time of CHRM increased, while that of PRED slightly decreased. Also, higher $\mathrm{pH}$ values caused distortion of peak shape and decreased sensitivity. Thus, $\mathrm{pH} 3.0$ was selected for the best separation. Actually, the presence of phosphoric acid (buffer solution) affects the charge on the analyte and ultimately on their retention times. So, it is essential to optimize the $\mathrm{pH}$ and the ratio of buffer solution in the mobile phase for the best separation.

The chromatograms have broad peaks and long retention times, as observed by using low ACN and higher buffer concentrations. The analysis time reduced, when the ACN concentration was increased and the buffer concentration was decreased, and the peaks were sharp and more symmetrical. In the end, the mobile phase consisting of $\mathrm{ACN}$ and phosphate buffer in a ratio of 50:50 (v/v) with the $\mathrm{pH}$ adjusted to 3.0 was selected. For the best separation, the column temperature was
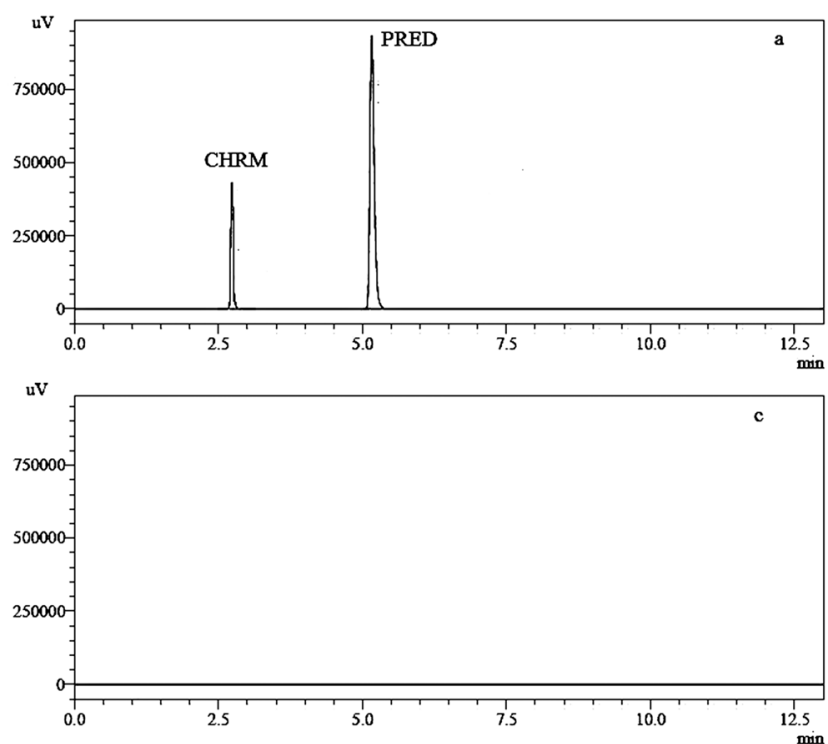

maintained at $30{ }^{\circ} \mathrm{C}$, and the flow rate was kept at $1.0 \mathrm{~mL} /$ min. Sharp and symmetric peaks were obtained by using a Thermo Hypersil ODS C18 column $(5 \mu \mathrm{m}, 4.6 \times 250 \mathrm{~mm})$ for HPLC analysis, at a detection wavelength of $254 \mathrm{~nm}$ (Figure 2.). The placebo solution (sodium metabisulphite, Tween-80) was also used in HPLC to asses any interfering peaks. The detection of components was done by injecting $20 \mu \mathrm{L}$ of the sample. The retention times for CHRM and PRED were 2.81 and $5.07 \mathrm{~min}$, respectively by HPLC as shown in Figure 2. It was found that presence of excipients made no effect on the separation of both the drugs. Thus, the method would be applied for the determination of CHRM and PRED in their pharmaceutical formulations.

3.2. Validation Studies. The system suitability parameters were assessed for the chromatographic system, as they are conformity of chromatographic parameters that ensures the suitability and performance of the analytical system. The system suitability parameters including tailing factor $(T)$, resolution $\left(R_{\mathrm{s}}\right)$, capacity factor $\left(k^{\prime}\right)$, theoretical plates $(N)$, and asymmetry $\left(A_{\mathrm{f}}\right)$ are presented in Table 2. All critical parameters, as defined above, met the acceptance criteria and indicate good specificity of the analytical method for the assessment of stability of CHRM and PRED. The resolution factors were greater than 2 for PRED from the nearest CHRM peak, indicating the efficient resolution. The results in Table 2 show good resolution, good peak shapes, and reasonable testing time, under the optimized chromatographic conditions for the separation of CHRM and PRED.

The calibration curves were plotted based on the regression analysis of detector response versus concentration of the two

Table 2. System suitability data of reference solution of CHRM and PRED

\begin{tabular}{|c|c|c|c|c|c|c|c|}
\hline \multirow[t]{2}{*}{ ICH Criteria } & \multirow[t]{2}{*}{ Specification } & \multicolumn{3}{|c|}{ CHRM } & \multicolumn{3}{|c|}{ PRED } \\
\hline & & Day & Day 2 & Day 3 & Day 1 & Day 2 & Day 3 \\
\hline $\begin{array}{l}\text { Retention time } \\
\left(t_{\mathrm{R}} \text { in } \min \right)\end{array}$ & $\%$ RSD $<2$ & 0.23 & 0.15 & 0.32 & 0.11 & 0.12 & 0.72 \\
\hline Tailing factor $(T)$ & $<2.0$ & 1.07 & 1.19 & 1.06 & 1.16 & 1.10 & 1.06 \\
\hline Resolution $(R s)$ & $>2.0$ & - & - & - & 7.86 & 7.94 & 7.92 \\
\hline Capacity factor $\left(k^{\prime}\right)$ & $>1.0$ & 2.94 & 2.96 & 2.93 & 6.19 & 6.11 & 6.13 \\
\hline $\begin{array}{l}\text { Theoretical plates } \\
(N) / \text { meter }\end{array}$ & $>1000$ & 4546 & 4603 & 4531 & 5134 & 5225 & 5235 \\
\hline Asymmetry $\left(A_{\mathrm{f}}\right)$ & $0.8-1.2$ & 0.94 & 0.95 & 0.97 & 1.12 & 1.11 & 1.15 \\
\hline Area & $\% \operatorname{RSD}<2$ & 0.47 & 0.21 & 0.18 & 0.31 & 0.42 & 0.34 \\
\hline
\end{tabular}
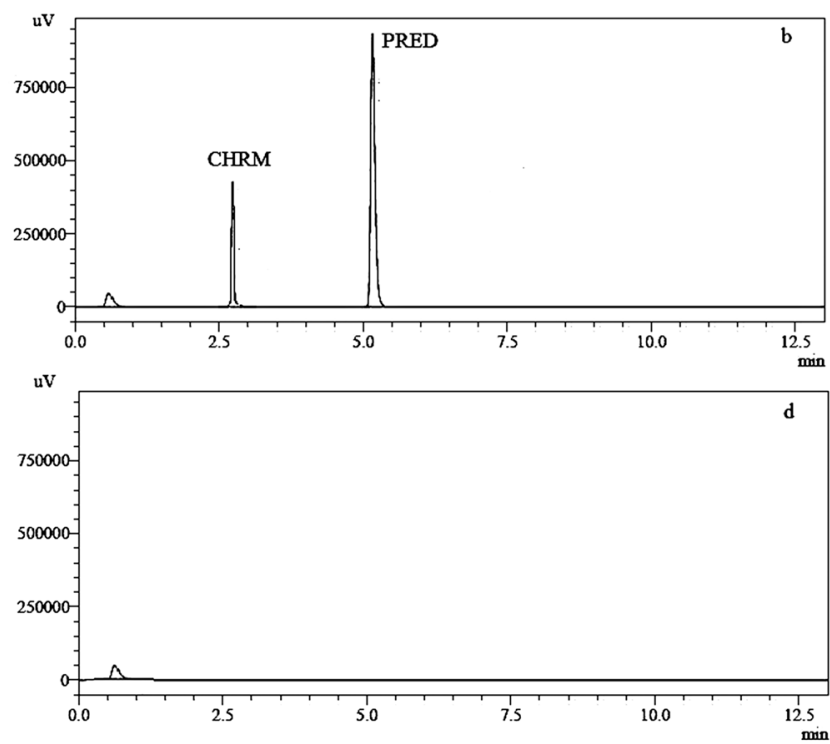

Figure 2. Typical HPLC chromatograms of the standard (a), sample (b), mobile phase (c), and placebo (d) (working conditions: mobile phase 50:50 [ACN-phosphate buffer, $\mathrm{pH}=3.0$ ] at $254 \mathrm{~nm}$, flow rate $1.0 \mathrm{~mL} / \mathrm{min}$, Column temp. $30^{\circ} \mathrm{C}$ ) 
Table 3. Regression data of CHRM and PRED by HPLC

\begin{tabular}{lcc}
\hline Parameters & \multicolumn{2}{c}{ Standards } \\
\cline { 2 - 3 } & CHRM & PRED \\
\hline Linearity range $(\mu \mathrm{g} / \mathrm{mL})$ & $10-70$ & $20-140$ \\
Slope & $466,156,514$ & $96,876,450$ \\
Intercept & 750,735 & $2,542,680$ \\
Standard error of slope & 303,168 & $2,309,835$ \\
Standard error of intercept & $13,667,870$ & 195,996 \\
Coefficient of determination $\left(R^{2}\right)$ & 0.9986 & 0.9994 \\
LOD $(\mu \mathrm{g} / \mathrm{mL})$ & 0.012 & 0.112 \\
LOQ $(\mu \mathrm{g} / \mathrm{mL})$ & 0.037 & 0.374 \\
\hline
\end{tabular}

Table 4. Recovery studies of CHRM and PRED by HPLC

\begin{tabular}{|c|c|c|c|}
\hline Analyte & $\begin{array}{l}\text { Concentration after } \\
\text { spiking }^{a}(\mu \mathrm{g} / \mathrm{mL})\end{array}$ & $\begin{array}{l}\text { Concentration found }^{b} \\
(\mu \mathrm{g} / \mathrm{mL}) \pm \mathrm{SEM} \text {; RSD }\end{array}$ & $\begin{array}{c}\text { (\%) Recovery } \\
\text { [BIAS] }\end{array}$ \\
\hline \multirow[t]{3}{*}{ CHRM } & & & $99.84[0.16]$ \\
\hline & & & \\
\hline & & & 9 \\
\hline \multirow[t]{3}{*}{ PRED } & & & \\
\hline & & 100.2 & $100.22[0.2$ \\
\hline & 125.0 & $7 ; 0.22$ & $99.87[0.13]$ \\
\hline $\begin{array}{l}{ }^{a} \text { Actu: } \\
{ }^{b} \text { All n } \\
\text { SEM: } \\
\text { RSD: } \\
\text { Accep }\end{array}$ & $\begin{array}{l}\text { concentration each o } \\
\text { easurements were mac } \\
\text { tandard error of mean } \\
\text { elative standard devia } \\
\text { ance criteria (RSD }<\end{array}$ & $\begin{array}{l}\mathrm{CHRM}=20 \mu \mathrm{g} / \mathrm{mL}, \mathrm{PR} \\
\text { in replicate of five. } \\
\text { on. }\end{array}$ & $\mathrm{D}=50 \mu \mathrm{g} / \mathrm{mL}$ \\
\hline
\end{tabular}

analytes by preparing standard solutions of CHRM and PRED at 7 different concentration levels. The calibration graphs showed good linearity within concentration range of 10 $70 \mu \mathrm{g} / \mathrm{mL}$ for CHRM and $20-140 \mu \mathrm{g} / \mathrm{mL}$ for PRED. The linearity was validated by the linear correlation coefficient values $(>0.998)$ with small intercept values.

The LOD and LOQ for CHRM and PRED were determined based on the signal-to-noise ratio.

LOD and LOQ determined by the proposed LC method were 0.012 and $0.037 \mu \mathrm{g} / \mathrm{mL}$ for CHRM while 0.112 and $0.374 \mu \mathrm{g} / \mathrm{mL}$ for PRED, respectively, as shown in Table 3 .

Accuracy of the method was determined by evaluating the recovery studies after spiking the known amount of standard drugs in commercial products. The recovery results were obtained between the ranges $99.48-100.12 \%$ and 99.83 $100.22 \%$ (Table 4 ) for CHRM and PRED by proposed HPLC method, respectively, which justified the suitability of the method for their intended applications.

Precision of the assay was determined in terms of repeatability (intra-day) and reproducibility (inter-day). Intra-day precision was determined by injecting 3 different concentrations (50,100, and $150 \%$ level of analyte under investigation) of standard solutions of CHRM and PRED $(n=5)$ on the same day. Meanwhile, the inter-day precision was determined by injecting the same concentration of standard solutions for 3 consecutive days. The relative standard deviation (RSD, \%) values for repeatability and reproducibility obtained were less than 1.72 and 1.47 , respectively, for CHRM while below 1.32 for repeatability and 1.42 for reproducibility assays of PRED (Table 5).

3.3. Forced Degradation Studies. Force degradation studies under stress conditions (Table 6) were performed for presenting the stability-indicating capacity of the proposed HPLC method.

The chromatograms (Figure 3) after forced degradation are presented, while the amount remaining and the extent of degradation are tabulated after each treatment. No degradations were observed for CHRM under acidic and for PRED under thermal stress. Thus, the extent of degradation was declared as none.

In contrast, significant degradation was observed under basic and acidic stress, and the remaining concentration of PRED was found to be 9.58 and 7.38 , respectively. Two impurity peaks at unique retention times $t_{\mathrm{R}}=3.85 \mathrm{~min}$ and $t_{\mathrm{R}}=4.58 \mathrm{~min}(\mathrm{AP}-2$ and AP-3, Figure $3 \mathrm{~b}$ ) were observed after basic degradation, while 3 impurity peaks at $t_{\mathrm{R}}=3.0 \mathrm{~min}$, $t_{\mathrm{R}}=4.25$, and $t_{\mathrm{R}}=4.72 \mathrm{~min}$ (DP-1, DP-2, and DP-3, Figure 3c) were observed under acidic stress. PRED was slightly degraded under photolytic conditions with unique impurity peak at $t_{\mathrm{R}}=3.56 \mathrm{~min}(\mathrm{PP} 2)$ but not significantly degraded under oxidative stress, the remaining amount was 87.54, and the impurity peak was observed at $t_{\mathrm{R}}=3.45$ (OP2). CHRM was slightly degraded under oxidative, photolytic, and thermal tress conditions with impurity peaks at $t_{\mathrm{R}}=1.98(\mathrm{OP} 1), t_{\mathrm{R}}=3.45(\mathrm{PP} 1)$, and $t_{\mathrm{R}}=2.0(\mathrm{TP} 1)$, respectively, were observed. As a result of these experiments, the proposed HPLC method was found to be specific for the analyzed active pharmaceutical ingredients.

Table 5. Precision studies of CHRM and PRED by HPLC

\begin{tabular}{|c|c|c|c|c|c|}
\hline \multirow[t]{3}{*}{ Analyte } & \multicolumn{2}{|c|}{ Repeatability $(n=5)$} & \multicolumn{3}{|c|}{ Reproducibility $(n=5)$} \\
\hline & \multirow[t]{2}{*}{ Concentration $(\mu \mathrm{g} / \mathrm{mL})$} & \multirow{2}{*}{$\begin{array}{c}\text { Concentration found } \\
(\mu \mathrm{g} / \mathrm{mL}) \pm \mathrm{SEM} ; \mathrm{RSD}\end{array}$} & \multicolumn{3}{|c|}{ Concentration found $(\mu \mathrm{g} / \mathrm{mL}) \pm \mathrm{SEM}$; RSD } \\
\hline & & & Day 1 & Day 2 & Day 3 \\
\hline \multirow[t]{3}{*}{ CHRM } & 30.0 & $29.81 \pm 0.23 ; 1.43$ & $29.95 \pm 0.42 ; 0.98$ & $29.68 \pm 0.87 ; 0.84$ & $29.74 \pm 1.09 ; 1.08$ \\
\hline & 40.0 & $40.31 \pm 0.18 ; 1.02$ & $40.09 \pm 0.12 ; 1.12$ & $40.11 \pm 0.47 ; 1.47$ & $39.98 \pm 0.22 ; 1.11$ \\
\hline & 50.0 & $49.89 \pm 1.17 ; 1.72$ & $49.87 \pm 1.54 ; 1.22$ & $49.85 \pm 1.27 ; 1.45$ & $50.15 \pm 1.52 ; 1.44$ \\
\hline \multirow[t]{3}{*}{ PRED } & 75.0 & $74.34 \pm 0.22 ; 1.11$ & $75.34 \pm 0.22 ; 0.65$ & $75.11 \pm 0.32 ; 1.13$ & $75.21 \pm 0.32 ; 1.42$ \\
\hline & 100.0 & $99.23 \pm 0.43 ; 1.04$ & $100.21 \pm 0.33 ; 0.43$ & $99.83 \pm 0.21 ; 1.12$ & $100.11 \pm 0.21 ; 1.32$ \\
\hline & 125.0 & $125.16 \pm 0.42 ; 1.32$ & $124.32 \pm 0.41 ; 0.63$ & $125.08 \pm 1.53 ; 1.32$ & $125.21 \pm 1.23 ; 1.11$ \\
\hline
\end{tabular}

SEM: standard error of mean; RSD: relative standard deviation.

Acceptance criteria (RSD $<2.00)$.

Table 6. Forced degradation results of CHRM and PRED by HPLC

\begin{tabular}{|c|c|c|c|c|}
\hline \multirow[t]{2}{*}{ Nature of stress } & \multicolumn{2}{|c|}{ Amount remaining, mean $\pm \mathrm{SEM}(\%)^{a}$} & \multicolumn{2}{|c|}{ Extent of degradation } \\
\hline & CHRM & PRED & CHRM & PRED \\
\hline $0.1 \mathrm{M} \mathrm{HCl}(1 \mathrm{~h})$ & $99.43 \pm 0.21$ & $9.58 \pm 0.84$ & None & Significant \\
\hline $0.1 \mathrm{M} \mathrm{NaOH}(1 \mathrm{~h})$ & $86.32 \pm 0.23$ & $7.38 \pm 1.09$ & Non-significant & Significant \\
\hline $3 \% \mathrm{H}_{2} \mathrm{O}_{2}(1 \mathrm{~h})$ & $96.64 \pm 0.18$ & $87.54 \pm 0.43$ & Slight & Non-significant \\
\hline $6 \mathrm{~h}$ at $100^{\circ} \mathrm{C}$ & $92.86 \pm 0.11$ & $98.12 \pm 0.12$ & Slight & None \\
\hline $6 \mathrm{~h}$ under UV-254 nm & $94.32 \pm 0.18$ & $93.41 \pm 0.21$ & Slight & Slight \\
\hline
\end{tabular}



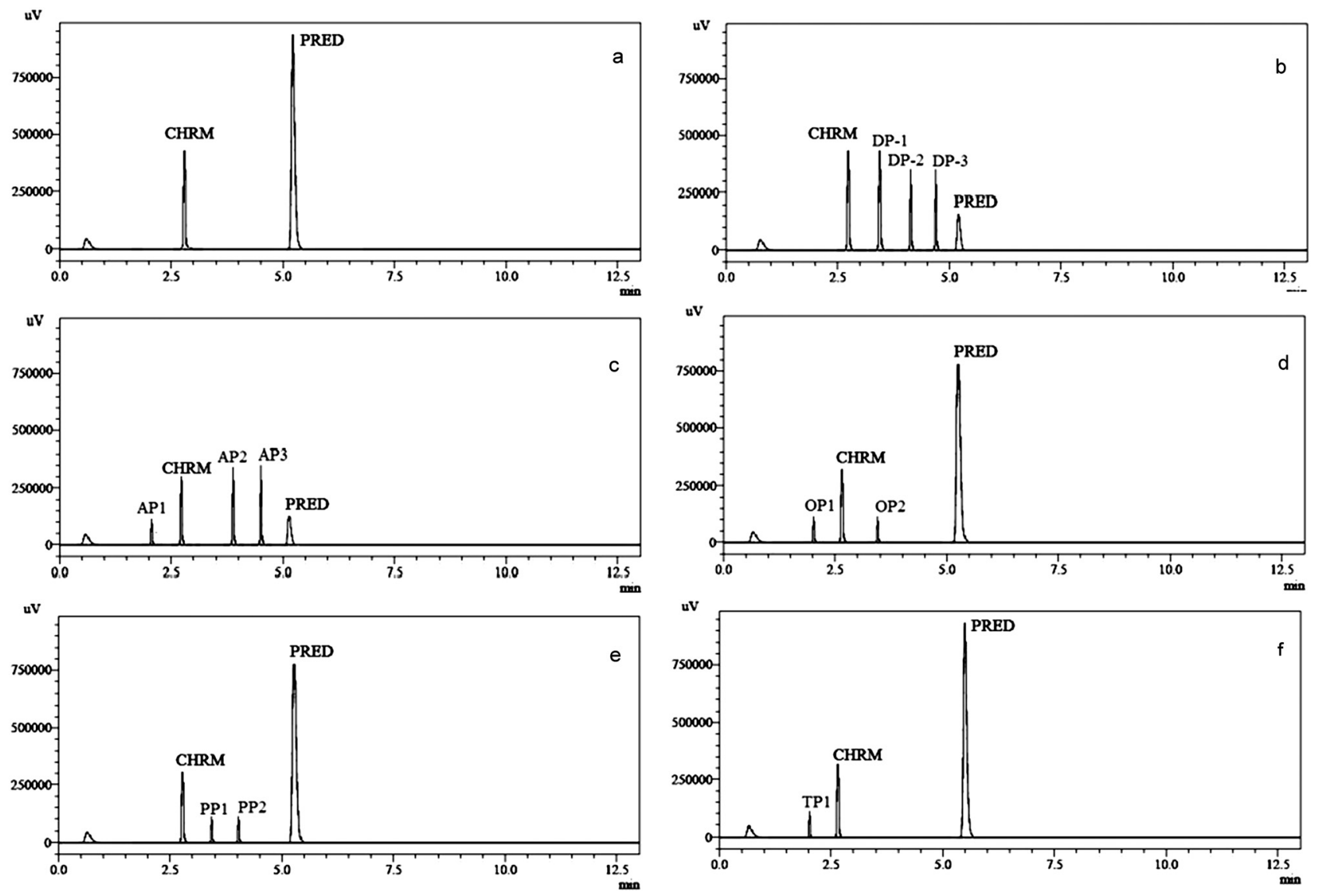

Figure 3. Chromatograms of CHRM and PRED under non-stressed conditions (a), acidic stress (b), basic stress (c), oxidative stress (d), photolytic stress (e), and thermal stress (f)

Table 7. Assay result of CHRM and PRED by HPLC in commercial formulation

\begin{tabular}{lcccc}
\hline Product & Analyte & $\begin{array}{c}\text { Label claim } \\
(\mathrm{mg} / \mathrm{mL})\end{array}$ & $\begin{array}{c}\text { Concentration found } \\
(\text { mean } \pm \text { SEM, mg; RSD, \%) })^{a}\end{array}$ & $\begin{array}{c}\text { Recovery } \\
(\%)\end{array}$ \\
\hline Solomin & CHRM & 4.0 & $4.09 \pm 0.34 ; 0.54$ & 102.3 \\
Injection & PRED & 10.0 & $10.16 \pm 0.51 ; 0.11$ & 101.6 \\
& \multicolumn{4}{c}{ Results are expressed as average of three measurements. } \\
\multicolumn{2}{l}{ Acceptance criteria (RSD $<2.00)}$. \\
\hline
\end{tabular}

3.4. Analysis of Commercial Formulation. The applicability of the proposed HPLC method was evaluated by examining the commercial injection (Solomin Injection ${ }^{\circledR}$ ), with the reported concentration of $4 \mathrm{mg} / \mathrm{mL}$ and $10 \mathrm{mg} / \mathrm{mL}$ for CHRM and PRED, respectively. The analysis was performed after dilution with mobile phase, and the percentage recoveries of CHRM and PRED were assessed in triplicate as mentioned in the label claim. It was concluded that the proposed HPLC method was sufficiently accurate and precise (Table 7) with recovery, and the RSD found ranged between $101.6-102.3 \%$ and $0.11-0.54 \%$, respectively.

\section{Conclusion}

A Sensitive and selective HPLC method was validated for the determination of CHRM and PRED in pharmaceutical formulations. The developed isocratic chromatographic method enabled unified quantification of CHRM and PRED with convincingly good precision and accuracy in pharmaceutical dosage forms. The behavior of chlorpheniramine and prednisolone was studied under different stressed conditions according to the ICH guidelines. The results of stability studies revealed that the degradation products formed under all stressed conditions. The total run time of analysis was found to be less than $7 \mathrm{~min}$. The recovery results were obtained between the ranges $99.48-100.12 \%$ and $99.83-100.22 \%$ for CHRM and PRED, respectively. The RSD values of repeatability and reproducibility for CHRM and PRED were found to be less than 2. The results of validation parameters show that the proposed method is simple, precise, accurate, and selective for the routine analysis of CHRM and PRED in pharmaceutical industries, where time and economy are essentially required.

\section{References}

1. Sanchaniya, P. M.; Mehta, F. A.; Uchadadiya, N. B. Chromatogr. Res. Int. 2013, 2013.

2. Heydari, R. Anal. Lett. 2008, 41, 965.

3. Dewani, A.; Barik, B.; Chipade, V.; Bakal, R.; Chandewar, A.; Kanungo, S. Arab. J. Chem. 2014, 7, 811.

4. Rojanarata, T. Int. J. Pharm. Pharmaceutic. Sci. 2012, 4, 444

5. Qadir, M. A.; Ahmed, M.; Shahzad, S.; Shafiq, M. I.; Razzaq, S. S.; Gulzar, A.; Ali, A. Lat. Amer J. Pharm. 2016, 35, 912.

6. Gallego, J. L.; Arroyo, J. P. J. Pharm. Biomed. Analysis 2003, 31, 873.

7. Suntornsuk, L.; Pipitharome, O.; Wilairat, P. J. Pharm. Biomed. Analysis 2003, 33, 441 .

8. Shibasaki, H.; Furuta, T.; Kasuya, Y. J. Chromatogr. B 1992, 579, 193.

9. Lou, H.-g.; Yuan, H.; Ruan, Z.-r.; Jiang, B. J. Chromatogr. B 2010 , 878,682 .

10. Zhang, Y.; Wu, H.-L.; Ding, Y.-J.; Xia, A.-L.; Cui, H.; Yu, R.-Q. J. Chromatogr. B 2006, 840, 116.

11. Ali, A.; Ahmed, M.; Mahmud, T.; Qadir, M.; Nadeem, K.; Saleem, A. Indian J. Pharm. Sci. 2015, 77, 515 .

12. Yang, Y. Chin. J. Pharmaceut. Anal. 2012, 32, 583.

13. Mazurek, S.; Szostak, R. J. Pharm. Biomed. Analysis 2006, 40, 1235.

14. Matysik, G.; Toczolowski, J.; Matysik, A. Chromatographia 1995, 40, 737.

15. Ram, V. R.; Dave, P. N.; Joshi, H. S. J. Chromatogr. Sci. 2012, 50, 721.

16. Akay, C.; Değim, İ. T.; Sayal, A.; Aydin, A.; ÖZKAN, Y.; Gül, H. Turk J. Med. Sci. 2008, 38, 167.

17. Guideline, I. H. T In Validation of analytical procedures: text and methodology Q2 (RI), International Conference on Harmonization, Geneva, Switzerland 2005, pp 11. 
18. Mohammad, A.; Yen, C. H.; Schneider, M.; Lowry, B.; Yerlikaya, F.; Whitesell, G.; Leisssa, B.; Faustino, P. J.; Khan, S. R. Anal. Method. 2018, 10, 1842.

19. Pharmacopeia, U. S In The Official Compendia of Standards (USP-40 2017), United States Pharmacopeial Convention, Rockville, MD, 2017.

20. Group, I. E. W In Validation of analytical procedures: text and methodology Q2 (R1), Proceedings of the International Conference on Harmonisation of Technical Requirements for Registration of Pharmaceuticals for Human Use 2005, pp 25.

21. Qadir, M. A.; Ahmed, M.; Hussain, W. A.; Tahir, M. S. Indian J. Pharm. Sci. 2015, 77, 434.
22. Ahmed, M.; Qadir, M. A.; Shahzad, S.; Waseem, R.; Tahir, M. S. Int. J. Chem. Pharm. Sci. 2013, 2, 536.

23. Ahmed, M.; Shahzadi, S. K.; Waseem, R.; Shahzad, S.; Ahmad, W. Inter J. Chem. Sci. Res. 2013, 3, 1.

24. Jehangir, M.; Ahmed, M.; Imtiaz Shafiq, M.; Samad, A. J. Anal. Meth. Chem. 2017, 2017, 1.

25. Tahir, M. S. Ahmed, M.; Shafiq, M. I.; Tariq, P.; Adnan, A.; Rashid, A.; Syed, Q.; Ali, Z. Lat. Amer. J. Pharm. 2017, 36, 2136.

26. Ivkovic, B.; Brboric, J.; Dobricic, V.; Cudina, O. Acta Chromatogr. 2018, 10.1556/1326.2017.00404. 